\title{
Steady Income and Costs Management in Municipalities: Two Crucial Factors in Sustainable Development
}

\author{
Ehsan Abdi ${ }^{1}$, Katayoon Pourmahdi ${ }^{2}$, Alireza Azarpajuh ${ }^{3} \&$ Iman Ghasemi $^{4}$ \\ ${ }^{I}$ Department of Applied Mathematics, School of Mathematics, Iran University of Science and Technology, \\ Tehran, Iran \\ ${ }^{2}$ International Business School, UniversitiTeknologi Malaysia, Kuala Lumpur, Malaysia \\ ${ }^{3}$ West Virginia University, Morgantown, WV 26506, USA \\ ${ }^{4 *}$ Department of Management, South Tehran Branch, Islamic Azad University, Tehran, Iran \\ *Correspondence: ImanGhasemi (Email: mani_sengani@yahoo.com)
}

\begin{abstract}
The first limitation to remove urban problems and service inefficiency in most of developing countries such as Iran is due to lack of financial resources, inefficient management,financial and budgetary control and cost planning.Organizations and different service and manufacturing companies compete with each other after strategic planning and considering advantages, disadvantages, opportunities and threats regarding production or rendering high quality and quantity services with lower costs. Steady development in economics and reduction in costs are of paramount importance in different aspects; and because municipalities are public organizations and have a frequent contact with the people, reducing municipality-related costs are doubly important. In fact, citizen's needs and expectations demand deeperconcentration of urban management especially urban areas in metropolises on cost management and sustainable development. In other words, not only is cost reduction a threat but also an opportunity which activates the unfulfilled potentials of the organization in order to avoidextra expense and make improvement. In this regard, culture-building practices and training along with application of modern technology are essential. In addition to policy making on cutting the costs, municipalities can take advantage of public and private participation. Analyzing the concepts of steady and irregular incomes as well as different methods of cutting the costs and earning steady incomes in municipalities, this article examines the modern methods of costs management for rendering more efficient urban services to the citizens.
\end{abstract}

Keywords: steady incomes, sustainable development, urban management, cost reduction, income management, cost management

\section{Introduction}

Municipalities are public institutions and are responsible for rendering public services in order to provideurban management and maintenance. Therefore, the way financial resources of municipalities are combined and supplied is of a crucial importance (Sharzeyi and Ghatmiri, 2001). In recent decades, urban management in Iran has faced serious challenges due to different social, cultural, political, administrative, financial and legal factors (MoeziMoghaddam, 2002). Obviously, one of the issues that has made these challenges more considerable is the explosive growth of cities due to the rapid growth of urban population (Iran Ministry of Internal affairs Deputy for Planning Office of Urban Affairs, 2002). Existence of more than $60 \%$ of the population of the country in urban areas, considerable growth rate of urban population compared with that of national population, allocation of considerable amount of income gained from value added tax to urban areas and the constant attention of the government to urban areas all show the importance of urban economics in Iran (Ghaderi, 2006). According to urban economics, factors such as increased activities of municipalities, people's growing expectations from them and problems caused by an increase in urban population increase the need for financial and income resources of the municipalities (Ghal'edar, 2003). Therefore, supplying the income and financial resources of municipalities is of paramount importance for on the one hand earning income by municipalities significantly affects their service rendering to citizens and on the other hand not only does lack of income cuts the provision of essential services for the urban areas but also it basically fails all urban plans (Jamshidzadeh, 2003). The reduction in municipalities' share from the government budget happened when the policy of self-sufficiency and self-sustenance of municipalities was put forward in 1983. Hence, municipalities have faced many problems regarding the financial relationship between municipalities and the government and persisting in the implementationof this process for a long time (Bahnmiri, 1999). So, lack of permanent income resources, at least for decreasing permanent costs, disrupts financial and budgetary planning of the municipalities. As a result, present income resources can't cover the increasing costs of municipalities in future (Ghaderi, 2006).Some scholars such as Pier Martin holds that in the third millennium the most important challenge for urban management originates in costs and earning income will be the cornerstone of policy 
making on the level of urban management (Martin, 1997). Therefore, municipalities need to have new and sustainable income resources to provide the citizens with services that require high cost.

\section{Urbanization and citizenship costs}

$70 \%$ of today's population lives in urban areas.Since these urban areas are the heart of economic, social and cultural activities, their problems become graver day by day. This increase is more drastic now. However, ten years ago it wasn't like that. Therefore, urban institutes are very important and any problems and shortcomings with them trouble the most important part of society. When one talks about urban costs decrease, attentions will be directed towards municipality in a large urban area like a mega city. However, the fact is that municipalities can't be successful in fulfilling such goal separately. Urban costs decrease is mutual, that is, decreasein municipality costs in rendering services and decreasing forced costs of citizens who are direct benefactors of urban services. The collaboration of these two factors would be fruitful in urban cost decrease (AmirAhmadi and Razavi, 2000).

Regarding the fact that urban life style is changing and one faces new issues and challenges in cities every day, the policy that suggests people should pay the citizen costs ought to be accepted. At present time, municipalities do not have access to other financial resources but tax. However, government anticipates and pays some financial aid for public transportation. But, life costs in cities especially mega cities are becoming higher due to the size of urban areas. The costs of a unit of urban services would be less because although the services are alike, costs differ. Hence, all costs should be added up, and then the total cost should be divided by the population of the city based on the conditions and situation of that city. However, it requires legal and administrative processes (Iran newspaper, urban management, 1/10/2011).

Supreme leader's Nowruzspeech in the beginning of the year 1393 (2014) implies the orientation of Islamic Republic of Iran's policies for putting in more efforts to improve economy and culture as well astheintroduction of the bill for resistance economy in the end of the year 2013 show that authorities and the people are not satisfied with economymanagement. That's why, the supreme leader believes that feeble effort is not enough to improve the situation and therefore the whole Iranian nation should have a jihadi effort to boost economy. Having mentioned the influential role of public in developing the country, supreme leader stated that improving the economy and culture is fruitless without the participation of public. We should not forget that an effort pays off when joined efforts are taken and eventually both parties obtain a shared goal. For sure it is fruitless if only one party tries to reform without gaining any support. Therefore, if there is a mutual harmony between municipalities and publicwe can suppose that urban costs reduction is possible (Iran newspaper, urban management, 4/7/2011).

\section{Concepts of Steady and Irregular Incomes}

One the most significant responsibilities of municipalities is the way they supply their financial resources to render essential services and commodities to the public. There are seven main financial resource categories along with more than a hundred subcategories in categorizing income resources of municipalities (Sharzeyi, 2008). Since, steady income heavily depends on sustainable development in economy which is crucially dependent on the way facilities and environmental services are used and protecting natural resources such as the way of benefiting from water, air, green belt and all urban facilities and areas, these steady incomes should enjoy the features of steadiness and maintaining the quality of urban areas. These two characteristics should always be reliable to design necessary plans for achieving them. Accordingly, all income resources which are generally affected by economic shock, chaos, rule alteration and fluctuation are not reliable and don't enjoy the feature of steadiness (AbbasiKashkuli and BagheriKashkuli).

Steady income has four characteristics:

1. Its resource should be unlimited or replaceable.

2. It should constantly bereceivable.

3. It should not have large fluctuation during different fiscal quarters.

4. It should increase alongside with an increase in costs but should not impact urban development.

Achieving new methods of supplying steady income resources without any negative economic, social and political consequences, can crucially affect the social satisfaction, facilitating development of urban areas and eventually effective urban management.Efforts have been increased to supply steady income resources for municipalities all around country.

As figure 1 suggests steady income in twenty two municipal zones of Tehran has increased in the last quarter of the year 2014. This income increase average changed from 10\% in 2013 to 15\% in 2014 (Tehran municipality, 2014). 


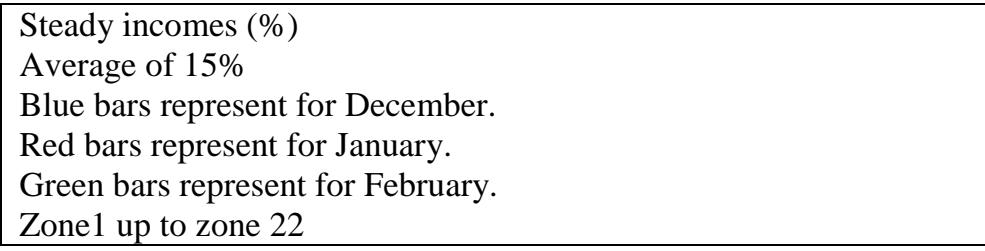

Figure (1): Steady incomes in the last quarter of 2013

\subsection{Methods of gaining steady incomes in municipalities}

Different methods can be defined based on cultural, economic and social conditions of the country. The most essential methods are (Ziyari, 2013):

Determining the role of government and municipality in developing urban areas

Essential income resources for developing and managing urban areas can be supplied by three sources:

- Local tax

- Urban service fees

- Government assignments of public works

Regarding this issue, at first the role and share of each these resources should be specified and then there should be a thoughtful planning for them.

Tax-Collection Clarification

- Drafting and approving of municipality income regulation as a macro regulation in the country

- Creating unity between policy making and presenting income bills of municipality

- Keeping up with modern technology and designing new and easy way of collecting tax

Creating willingness for paying tax

- Using different mass media and non-media tailored to the public's needs.

- Managing costs along with income increase

- Annual informing about different urban costs

Collection of Service fees

- Developing urbanization culture for making pay regulation in return for received services and reduction in costly responsibilities of municipalities.

- Rendering variant welfare and recreation services suitable for different income-earning strata and collection of total costs

- Assignment of public services to private sector and close supervision on the underway projects

\subsection{Application of new technology}

\section{Modern solutions for costs decrease in municipalities}

Not only does the useof mechanized garbage collection system in urban areas requiring citizen's cooperation to be operationalized reduce the costs of conventional garbage collection, but also it enhancesurban beauty and decreases scattered sources of pollution.Moreover, another way for earning income is to use such dirty goldthat can be reused asfertilizer and recycled stuff. It also can be profitable. Mashhad municipality has initiated such process to some extent but it seems that the variety of products that can be made from recycling is not that much accounted for or there isn't essential investment. Even making use of other types of household waste can be a huge source of energy and income for municipalities and cities. Also, attracting foreign investors into such process would be of great help. Moreover, using solar energy systems can be a solution to substantially decrease the municipality current costs. These systems whose technology is available in our own country can be used to light up parks and urban areas like most of the countries. However, bearing such costs is worth when citizens protect them as their own properties. Utilizing this method, municipalities can decrease the costs of using other types of energy. In addition, making use of energy efficient devices such as different smart lighting systems which are introduced into market nowadays and discarding older and energy-wasting devices can greatly reduce the costs. Further, painting may also be effective in using energy more efficiently. Since, painting public places using bright and happy colors can reflect light and lead to less utilization of lighting systems. Furthermore, some social abnormal behaviorcan be stopped by showing some visual happiness to people. 
Steady Income and Costs Management in Municipalities: Two Crucial Factors in Sustainable ..

\subsection{Reducing public transportation costs}

Equipping different means of public transportation by virtue of private sector and municipalities planning and policy making can lower gasoline consumption, air pollution, accidents. Therefore, road safety in urban areas increases. Providing all urban areas with this type of public transportation as well as public support in using and protecting it can considerably reduce traffic jam, air pollution and lack of parking space.

\subsection{Renovating urban roads and passages}

Municipalities constantly renovate roads and passages but due to lack of harmony between servicerendering organizations involved in such process and municipalities, the costs paid are wasted and become many times larger.

Lack of harmony between these organizationscauses so much digging resulting in unbeautiful scenes and rough and nonstandard roads.This problem not only makes public unsatisfied but also increases car depreciation costs some of which are directly related to municipalities. Therefore, unity between organizations in charge of rendering urban services removes these redundancies.

\subsection{Provision of camps for travelers and pilgrims}

Provision of temporary and permanent camps can be a source of income and a source for lowering the costs. When travelers gather together in one or several different places reduces the costs of services such as garbage collection and so on and so forth.

\subsection{Creativity in utilizing urban facilities}

Creativity and innovation are of paramount importance in this world. For instance, municipalities pay high costs for landscaping service and its maintenance. Planting strong plant species can be one solution for lowering the cost. Planting drought-tolerant and multiple season plants is another way for cutting the costs. In some cities of the country public areas have been used as an investment to plant fruit trees. That's is, instead of planting fruitless trees in squares and boulevards municipalities have planted olive trees whose fruit is not that popular among people and pedestrians and about nine to twelve tons of olive is picked in urban areas each year.

\subsection{Psychology of communication}

Those people who always take the first step to communicate with others are the most successful people. They communicate with their customers and clients and get their ideas about the commodities. It can be the best advertisement for the company. Because, they get familiar withier customers' ideas without bearing any costs and they will remove the shortcomings as much as possible in order to improve the quality of their products and services.

\subsection{Improving knowledge level}

Today we live in a world in which obtaining knowledge highly encourages us to achieve the peaks of success and for working professionally we should systematically learn the job. This goal is achievable only by knowing and learning the necessary skills. Skill and knowledge are like two parallel and supplementary lines that help the organization achieve the success little by little. Human resource enjoying necessary knowledge and skill about its duty will substantially reduce the costs of the organization such as training, making up for mistakes, wasting of time and also improves the organization.

\subsection{Electronic municipality (E-municipality)}

Electronic municipality is an organization which quickly, accessibly and safely renders its services within municipality area of responsibility drawing on information technology to citizens. E-municipality gives 24-hour services in city without time-space limit. Features of E-municipality are as follows:

- Dossiersare discarded and transformed into digital information

- Department responsible for answering phone calls is eliminated

- Electronic communication is of crucial importance and should be applied in departments responding to citizens.

- A location is dedicated to citizens for exchanging ideas over municipal and municipality performance.

- Renovation tax and other tax are paid online.

- Paperwork regarding municipality dossiers is eliminated and frequenting to municipality would decrease.

- Updated notification about urban development and its related issues are given.

\subsection{Electronic citizen (E-citizen)}

Despite the problems regarding air and sound pollution, traffic, wasting energy and the importance of time, the need for institutionalizing and utilizing electronic services is essential. Today, we are witnessing that 
banks are brilliantly moving towards cyberization in a way that frequenting of clients and face to face attending have greatly reduced and public can get services without attending the banks.

Municipalities should also move towards cyberization. As a result, there would be lower traffic jam and the costs for reducing air pollution and renovating urban roads and passages decreases. This only happens when citizens receive essential training on how to use electronic services and they also should try hard to utilize such facilities. Recently, Mashhad municipality has launched comprehensive plans to render electronic services such as holding free E-citizen training sessions and paying bills electronically. This process still continues (Asnafi, 2009).

\section{Experiences of Iran's mega cities in decreasing the costs}

Establishing cost management committee which can improve the financial resources and efficiency can be one of the most crucial actions for reducing costs in an organization like municipality. Policy making for costs reduction is the responsibility of this committee. The position and the role of such committee should be established in different levels in a way that provoke the creativity of all the staff and their suggestions. Analyzing costs, identifying costly services, consulting, supervising the cost decrease solutions, designing and approving improvement projects, planning, and project management and supervising them to make sure they are carried out quickly and perfectly till the time of utilization all are committee's responsibilities.

Some activities being used by Mashhad municipality in order to decrease the costs are as follows:

1. Decreasing electricity cost using energy-saving light bulbs and reminding the staff

2. Organizing rental and private vehicles used by municipality

3. Installing stone curbs instead of concrete ones

4. Utilizing geographical information system in urban management

5. Installing office automation systems in municipality of Mashhad

6. Installing a comprehensive statistical information system

7. Using electrical energy-saving devices with higher productivity and quality

Carrying out these cost management plans reveals how to identify costly undertakings by analyzing andhow to lower municipality costs by participation of staffs and making use of their creativity.

Execution of different plans in Tehran municipality in recent years has revealed the unanimous determination for cutting costs, increasing profit and productivity and optimization of implemented plans in so far as Tehran municipality Director of Finance, Planning and Performance considered reduction of costs as one way of increasing profit in such organization. He also suggested that cost management has been fully discussed from the beginning of this period of management in Tehran; therefore, by creating committees in different departments such as twenty two municipal zones, offices, organizations and companies an effort has been undertaken to develop and institutionalize the strategies. For instance, Art Management Committee in Tehran municipality was officially launched in 2005 as one of the high committee workgroups of financial and resources improvement. Executive committees designed and implemented comprehensive plans in order to execute costs decrease strategy. These plans are as follows:

1. A comprehensive plan for reducing electricity cost using six-solution policy

2. A comprehensive plan for replacing grass with bushy and groundcover plants

3. A comprehensive plan for anti-icing and de-icing of roads using chemical solution

4. A comprehensive plan for organizing private and rental vehicles of municipality

5. A comprehensive plan for changing the method of widening the two way streets to one way and commercial use of their deserted areas.

6. A comprehensive plan for covering the open creeks of streets and establishing surface water collection network utilizing pipes.

7. Installing stone curbs instead of concrete curbs in backstreets and avoiding the installation of curbs in parks

8. A comprehensive plan for using Global System instead ofutilizing units of cost index in some urban projects

9. A comprehensive plan for organizing warehouses and properties of different municipal zones.

10. A suggested comprehensive plan for renovation of fountains and urban areas lighting

11. A comprehensive plan for the application of Geographical Information System in urban management.

12. A comprehensive plan for installation of office automation systems in Tehran municipality

13. A comprehensive plan for facilitating the process of holding tender sessions and managing Tehran municipality projects

14. A comprehensive plan for improving the system for discount, exemption and financial aids provided by Tehran municipality

15. A comprehensive plan for building recycling old tires for utilization in producing asphalt and flooring.

16. A detailed plan for installing urban roads and asphalt management system. 
Table (1) shows the detailed plans for cost decrease and the amount of reduction of their total cost in Tehran municipality (Masoumzadeh, 2010). A brief look at table (1), which is provided by the Organization for Controlling Municipality Performance in 2010, shows the reduction in costs after implementation of comprehensive plans. If these plans are implemented in larger scales, they prevent waste of financial resources in executed plans of municipalities.

Table (1): Cost Reduction Comprehensive Plans

\begin{tabular}{|c|c|c|}
\hline $\mathrm{R}$ & Title of Comprehensive Plan/Improvement Project & Estimated Cost Reduction (billion Tomans) \\
\hline 1 & reducing electricity cost using six-solution policy & 4.5 \\
\hline 2 & $\begin{array}{c}\text { replacing grass with bushy and groundcover plants for some parts of } \\
\text { landscape }\end{array}$ & 4 \\
\hline 4 & organizing private and rental vehicles of municipality & 10.6 \\
\hline 5 & $\begin{array}{l}\text { changing the method of widening the two way streets to one way and } \\
\text { commercial use of their deserted areas. }\end{array}$ & 14.1 \\
\hline 7 & $\begin{array}{l}\text { Installing stone curbs instead of concrete curbs in backstreets and avoiding } \\
\text { the installation of curbs in parks }\end{array}$ & Under estimation \\
\hline 8 & $\begin{array}{l}\text { using Global System instead of utilizing units of cost index in some urban } \\
\text { projects }\end{array}$ & $\begin{array}{l}10 \% \text { of the related budget spent on building } \\
\text { construction and } 12 \% \text { on Road construction }\end{array}$ \\
\hline 9 & organizing warehouses and properties of different municipal zones & 5 \\
\hline 13 & $\begin{array}{l}\text { facilitating the process of holding tender sessions and managing Tehran } \\
\text { municipality projects }\end{array}$ & under estimation \\
\hline 14 & $\begin{array}{l}\text { for improving the system for discount, exemption and financial aids } \\
\text { provided by Tehran municipality }\end{array}$ & under estimation \\
\hline 15 & $\begin{array}{l}\text { building a factory for recycling old tires to be utilized in producing } \\
\text { asphalt and flooring. }\end{array}$ & 18 \\
\hline 16 & installing urban roads and asphalt management system & under estimation \\
\hline
\end{tabular}

\section{Conclusion}

The first limitation to remove urban problems and service inefficiency in most of developing countries such as Iran is due to lack of financial resources, inefficient management, financialand budgetary control and cost planning. According to what has been mentioned in this article, one can conclude that municipality as a public institution being responsible for urban management should make an effort to reduce its dependence on irregular incomes to supply its financial resources. It should also provide the citizens with essential commodities and services via increasing its steady income. Reducing costs via the implementation of comprehensive costreduction plans can enable municipalities to prevent waste of financial resources and to improve urban sustainable development. Otherwise, municipalities will face substantial cultural, social and economic challenges in urban management. Therefore, researcher suggests implementation of new methods in supplying financial resources and steady incomes and use of the Iran's municipalities or foreign countries municipalities' experiences.

\section{References}

[1]. Asnafi, A (2009), Modern Information Technologies and Cost Reduction, Social Sciences Education Improvement.

[2]. Martin, P (1997), ThirdMillennium Management,Bathos Press, Universityof South Australia.

[3]. Razavi and AmirAhmadi, (2000), Urban Development against Modernism and the Requierments of Plannig (translated by Sayyed Mahmoud NejatiHosseini), Urban Management Quarterly: second version, Tehran, Ministry of interior

[4]. Jamshidzadeh, E (2002), Cost and Finance Analysis of Iran's Municipalities, Iran Management and Planning Research Quarterly: first version, fourth year.

[5]. Iran Newspaper, Urban Management (1/10/2011), Municipalities and Income and Costs Unoptimized Management.

[6]. Iran Newspaper, Urban Management (5/10/2011), Urban Management and Cost Imposition on Citizens.

[7]. Ziyari, K, Mahdavi, A, MahdiaynBahnmiri, M ( 2013), Analysis and Identification of financial Resources and Developing Solutions to improve the Steadiness of Municipalities incomes, under research, Mahabad Municipality, Urban Management Quarterly, version 31.47

[8]. Tehran Municipality, (2014), Report for Analytical Results of Performance of 22 Municipal Zones in 2014, Deputy for Planning and Urban Development of Management Performance and Improvement Headquarters.

[9]. Sharzeii, Gh (2008), Identification and Analysis of Iran Municipalities' Income Resources, Urban Management Quarterly, second version.

[10]. Sharzeii, Gh, Ghatmiri, M (2011),Analysis of Methods of Supplying Financial Resources of Municipalities (Case Study: Structure of Financial Resources of Shiraz Municipality),Urban Space Management Conference Article Collection.

[11]. AbbasiKashkuli, Kashkuli, Mohammad Ali and Ali (2010), Methods of Supplying Steady Income for Municipalities of Iran, AndishehAndPazhuhesh.

[12]. Ghadei, Jafar (2006), Evaluation of Financial and Income Regulation of Iran's Municipalities, Economic Analysis Quarterly, third edition, third version 
Steady Income and Costs Management in Municipalities: Two Crucial Factors in Sustainable ..

[13]. Ghaledar, H (2003), Comparing Income Resources of Municipalities in Iran's Metropolises and Analysis of Its Profound Effects, A Master of Art Dissertation, Shiraz University

[14]. Moezimoghaddam, Hossein (2002), Methods of Income Resource Supply of Municipalities, Deputy for Planning and Development, Iran's Department Municipalities Department Publication, Tehran.

[15]. Masoumzadeh, Jafar (2010), reviewing Tehran Municipality Experiences Regarding Cost Reduction, Executive and Scientific Events, EghtesadShahr.

[16]. Deputy of Development of Interior Ministry Planning Office, (2002), A Review on Municipalities' Urban and Research Plan, Journal 29.

[17]. NajjariyanBahnmiri, M (2008), An Analysis of Income and Costs of Mazandaran Province Grade seven Municipalities and the factors affecting it from 1988 to 1998. 